\title{
DIREITOS HUMANOS E A DOUTRINA SOCIAL DA IGREJA CATÓLICA: APROXIMAÇÕES E DIFERENÇAS
}

\author{
[Human rights and the social doctrine of the catholic church: \\ approaches and differences]
}

\author{
ALEX ROSA ${ }^{1}$ \\ JACKSON DA SILVA LEAL ${ }^{2}$ \\ GABRIEL DELLA BRUNA ${ }^{3}$
}

\begin{abstract}
Resumo
O presente trabalho trata de uma análise sobre o desenvolvimento e consolidação dos direitos humanos a partir de uma relação eurocêntrica histórica de sua existência e a atual pretensão de universalidade, mas que em verdade demonstram sua seleção de direitos a serem garantidos pautados nos valores econômicos e sociais característicos da ética burguesa resultando numa póscolonialidade com marcas de dominação e exclusão. Em seguida, observar-se-á a composição do direito canônico e sua relação com as formas de Estado e sua atual posição enquanto defensora dos direitos humanos, porém crédula do direito natural, o que, dentro de sua relação de fé e verdade, implica em influências religiosas nos Estados seculares. A partir disso, então, busca-se aproximar as visões acerca dos direitos humanos numa perspectiva religiosa e num viés jurídico civil, analisado pontos de divergência e espaços comunhão de ideias. Esse trabalho busca problematizar e agregar elementos de compreensão quanto a questão da espiritualidade (religiosidade), inseridas tanto em questões legislativas quanto no campo da política. Metodologicamente esse trabalho parte de análise teórica, desde revisão bibliográfica, utilizando método dedutivo e tendo como material dessa pesquisa analítica a literatura tanto da religiosidade católica e seus postulados constantes nas encíclicas e doutrina social, quanto da definição tanto liberal quanto critica de direitos humanos.
\end{abstract}

Palavras-chave: direitos humanos, doutrina social da igreja, direito natural

\section{Abstract:}

The present work deals with an analysis on the development and consolidation of human rights based on a historical Eurocentric relation of their existence and the current pretension of universality, but which in fact demonstrate their selection of rights to be guaranteed based on economic and social values characteristic of bourgeois neoliberal ethics, resulting in a postcoloniality with marks of domination and exclusion. Next, the composition of canon law, its relationship with state forms and its current position as a defender of human rights, but credulous

\footnotetext{
${ }^{1}$ Mestrando em Direito (UNESC), Graduado em Direito pela (UNESC); professor de filosofia no cursinho pré-vestibular comunitário Navegar; membro do Grupo de Criminologia Critica Latino-americana (UNESC); endereço e-mail: alexdarosa@hotmail.com.br

${ }^{2}$ Doutor em Direito (UFSC), mestre em Politica Social (UCPel), professor da graduação e programa de pósgraduação (PPGD UNESC), coordenador do grupo de Criminologia Critica Latino-americana (UNESC); advogado inscrito na OAB/RS, endereço e-mail: jacksonsilvaleal@gmail.com

${ }^{3}$ Graduando em Direito pela (UNESC); bolsista de iniciação científica (UNESC); membro do Grupo de Criminologia Critica Latino-americana (UNESC); endereço e-mail: gabrieldellabruna@gmail.com
} 
of natural law, will be observed, which, within its relation of faith and truth, implies in religious influences in secular states. From this, then, we seek to approach the views about human rights from a religious perspective and a civil legal bias, analyzed points of divergence and spaces of communion of ideas. This work seeks to problematize and add elements of understanding regarding the issue of spirituality (religiosity), inserted in both legislative and policy issues. Methodologically this work starts from a theoretical analysis, from a bibliographical review, using a deductive method and having as material from this analytical research the literature both of Catholic religiosity and its postulates in the encyclicals and social doctrine, as well as the liberal and critical definition of human rights.

Keywords: human rights, social doctrine of the church, natural law

DOI: 10.7764/RLDR.9.117

\section{INTRODUÇÃO}

Buscando estabelecer uma relação entre os Direitos Humanos (D.H) - assumidos pela sociedade civil - e os valores próprios ao catolicismo, o presente estudo, na modalidade de ensaio, organiza pontos de contato entre ambas esferas, entendendo espaços de proximidade e apoio mútuo, mas também de afastamento e conflito.

Para isto, primeiramente se tomara os D.H já em sua perspectiva crítica, remontando sinteticamente sua constituição histórica para justamente nesse ponto inserir uma inflexão crítica acerca das problemáticas atinentes a sua composição, daqueles que são incluídos ou excluídos por esse discurso, segundo Martinez: "a sociedade que formalmente reconhece e garante direitos humanos, porém que os cumpre somente a partir da totalidade, a partir da mesmice; a exterioridade é excluída para desfruta-los. "(2015, pg. 69)

Fato é que se constitui um desafio fazer com que os direitos humanos não se subordinem a sua origem eurocêntrica e colonial, excludente das realidades marginais e oprimidas, fazendo-se necessária sua utilização enquanto ferramenta contra-hegemônica que rompa com as gritantes violências a humanidade, consequentes das mais diversas formas de dominação e exploração, sendo esta uma exigência ética séria nos tempos contemporâneos. (SOUSA SANTOS, 2009, pg. 10)

Os conflitos e tragédias humanitárias ocorridas no último século, não obstante as violentas realidades atuais, ensejam uma defesa rigorosa aos direitos humanos, enquanto espaço em que se destaca a posição das Igrejas como defensoras assíduas dos Direitos Humanos, em especial, a igreja Católica. A seleção dessa vertente religiosa se dá em especial pela majoritária influência histórica dela, principalmente outrora posição enquanto legisladora e regente do Estado, assim como pelo vasto material teórico documental organizado e sistematizado pela instituição. A respeito, se tomará principalmente o documento "Compêndio Doutrina Social da Igreja" (2011) com ponto de análise as orientações da Igreja ao Mundo. 
ISSN 0719-7160

Nesse bojo, um estudo sobre as diferenças fundamentais entre as leis dos homens e as leis de Deus, as diferenças entre os posicionamentos dos Estados Laicos e os valores/direitos afirmados pela Igreja Católica, serão tomados pelos autores 5 pontos de contato entre as duas esferas, comparativamente: a igualdade, a vida, visão positiva do trabalho, a família, a tolerância e liberdade de consciência.

Os desafios se dão tanto a nível secular, nos conflitos próprios aos movimentos sociais, quanto a nível canônico e os desafios teológicos interiores à própria instituição, o que torna a interação de ambas esferas - proporciona pela democracia - um espaço de construção e colaboração. Nesse sentido, aborda-se o tema da relação Direitos Humanos na interface com a questão da religiosidade, seus pontos de convergência e conflito, abordando a temática desde a perspectiva da Teoria Crítica dos Direitos Humanos e sua relação com a Teologia da Libertação que em grande medida orienta a ideia de teoria crítica jushumanista.

\section{DIREITOS HUMANOS SOB A PERSPECTIVA CRÍTICA}

Primeiramente se faz importante delimitar que concepção de direitos humanos se tem trabalhado para efeito desse trabalho, tendo em vista que Direitos Humanos se constitui em uma categoria ou mesmo vocábulo polissêmico, comportando uma serie de definições, inclusive absolutamente antagônicas.

Como demonstra Costas Douzinas (2008), direitos humanos tem sido operacionalizado inclusive como estratégia de mercado como forma de legitimação e aceitação; ou ainda poderia se referir uma concepção absolutamente deturpada de direitos humanos conservador, em que somente determinada fatia da sociedade faria jus (a fatia definida como de bem), e ainda a mais tradicional, de cunho liberal progressista que se cinge a uma compreensão jushumanística de definições legais, tratados e acordos internacionais, e que se permite uma perspectiva universalista ou mesmo colonial burguês eurocentrada dos direitos humanos - o modus vivendi europeu como exemplo ao resto da humanidade. Nesse trabalho se busca resgatar alguns elementos característicos da cristandade, que se alinham com a perspectiva crítica dos direitos humanos desde uma linha de teologia da libertação enquanto cristandade transformadora, a constituir o caráter espiritual do processo de tomada de consciência e transformação.

Assim, Alejandro Rosillo Martinez bem explica que os obstáculos que enfrentam os direitos humanos para escaparem de sua definição burguesa de humanidade e se tornem de fato para pessoas, povos e comunidades vítimas de desigualdades de poder que possam se assumir 
seu papel ativo na história e no mundo, em especial, quanto a necessidade de uma realidade jurídica latino-americana, ou a epistemologia do sul (MARTINEZ, 2015).

A partir de então estabelece cinco principais riscos a fundamentação dos direitos humanos:

a) Dogmática: é a fundamentação que busca estabelecer um ponto de origem, uma justificativa irrevogável, de lógica e verdade tão profunda que não caberia discuti-la em nenhum momento posterior, sendo assim, excluída do alcance daqueles que não a constituíram.

b) Pensamento único: é a postura que compreende os direitos humanos enquanto pressupostos de um pensamento político-econômico dominante, hegemônico, um posicionamento (neo)liberal que eleva o mercado ao status de regulador máster da sociedade, o principal direito a ser defendido.

c) Pensamento débil: consiste na fundamentação não marcada por nenhuma base específica, por consequência, flexionando as justificações ao ponto de não as encontrar, fator excludente de realidades físicas, reais de povos e comunidades marginalizadas.

d) Reducionismo: modelos em que se subsumi a justificação dos direitos humanos a partir de pontos únicos, diminutos e que excluem possibilidades de outras formas de existências, principalmente o jusnaturalismo e o positivismo ideológico, com características historicistas e distantes de práxis.

e) Etnocentrismo: encontra-se a dificuldade em superar o paradigma eurocêntrico dos direitos humanos, que toma como um único modelo de homem e vida existente o homem burguês europeu, numa obrigação que além de excluir as realidades marginais exerce forte coerção as demais realidades que importam um estilo de não condiz com suas condições locais específicas. (MARTINEZ, 2015)

Encontra-se então o desafio paradoxal acerca da universalidade dos direitos humanos: na medida em que assumem uma pretensão universal, carregam frequentemente suas características (neo) liberais e totalizantes de um conjunto de direitos que em muito se aproxima de uma ética, um modelo de vida que tem como pressuposto e condição a exclusão e exploração de povos marginais, ignorando as realidades especificas e regionais de outras localidades.

Segundo Edgardo Lander:

Essas dificuldades devem-se, em larga medida, ao fato de que o neoliberalismo é debatido e combatido como uma teoria econômica, quando na realidade deve ser compreendido como o discurso hegemônico de um modelo civilizatório, isto é, como uma extraordinária síntese dos pressupostos e dos valores básicos da sociedade liberal moderna no que diz respeito ao ser humano, riqueza, natureza, história, ao progresso, ao conhecimento e boa vida. (2005, pg. 8)

A declaração universal dos direitos humanos de 1948, marcada pelo recém pós-guerra, é incongruente ao pensar nas suas limitações intrínsecas: seu principal órgão regulador ou organizador, a ONU, constitui-se em tensão política similar entre os países desenvolvidos 
ISSN 0719-7160

envolvidos em guerra que tentam assegurar um mínimo acerca da "dignidade humana", sem ao menos por em cheque o campo que sustenta as práticas de desigualdade, que é o capital em suas formas varias formas.

No Capitalismo, só uma coisa é universal, o mercado. Não existe estado universal, justamente porque existe um mercado universal cujas sedes são os estados, as Bolsas. Ora, ele não é universalizante, homogeneizante, é uma fantástica fabricação de riqueza e miséria. Os direitos do homem não nos obrigarão a abençoar as "alegrias" do capitalismo liberal do qual eles participam ativamente. (DELEUZE, 2008, pg. 213)

Deste modo, propõe-se a tratar dos direitos humanos a partir de uma perspectiva crítica que supere fundamentações equivocadas, limitadoras, como bem assinaladas por Rosílio, mas que sim ultrapassem o atual paradigma de vida (neo)liberal burguês explícito nos valores consagrados pelas declarações de direitos humanos, inclusive, totalmente incongruentes em sua ordem de aparecimento, ressaltando mais uma vez sua relação com um modelo de vida não global, e sim forçosamente hegemônico.

Saídas a esses obstáculos mostram horizontes de esperança a partir da organização de grupo em torno de causas e reivindicações; fazendo das minorias e dos oprimidos massa forte de resistência capaz de promover mudanças, como observados os direitos sociais de terceira geração conquistados principalmente por grupos organizados e militância politica no ultimo século e que continuam a afrontar os posicionamentos dominantes, fazendo crer e realizar os direitos humanos como campo e espaço de luta, e ainda como percurso e construção politica como definia Joaquin Herrera Flores (2009); a partir de realidades diversas com culturas diferentes mas que primam pela libertação dos marginalizados e dos excluídos (SOUSA SANTOS, 2014).

A atual crise dos direitos humanos passa por sua fundamentação. As declarações, embora prometessem a emancipação humana, em verdade promoveram uma emancipação política de classes privilegiadas e dominantes (LUNA; OLIVEIRA, 2017).

Contudo, evitando incorrer em fundamentações metafísicas, que em grande medida se aproximam de um jusnaturalismo, ou em embasamentos pautados por uma política (neo)liberal dos países desenvolvidos, os direitos humanos precisam ser tratados no âmbito dos direitos civis considerando aspectos físicos, realidades fáticas em um mundo de desigualdades, com uma maior observância a que direitos são almejados e como são tutelados pelos Estados, ou seja, como preconizava Herrera Flores, desde uma perspectiva material de construção e concretização, sempre liminar e inacabada (FLORES, 2009). 
A seguir se tomará a Doutrina Social da Igreja Católica, junto a outros documentos de apoio, com fito de observar por outro vértice as contribuições desta importantíssima instituição na defesa dos D.H, mas também de compreender alguns desafios que tencionam essa influência religiosa nos Estados Laicos.

\section{ENTRE SOREN KIERKEGAARD E TOMÁS DE AQUINO - QUE SÃO DIREITOS HUMANOS?}

Como ponto central ao catolicismo, o direito natural será tomado numa perspectiva comum e enquanto ética transcendental de existência que deve exercer influência normativa na condução da vida e das escolhas. Ordenamentos divinos que escapam ao alcance do homem modificá-los e que constituem a essência do dever-ser, relacionando uma realidade de fé a uma prática secular.

Segundo a igreja católica, a relação do homem com Deus se da a partir da criação e da revelação. Das rupturas a essa relação, com a vinda de Jesus Cristo, constitui-se a nova e eterna aliança, que inclusive não pode ser rompida. As consequências desse fato, em Mateus 16-19 "E eu te darei as chaves do reino dos céus; e tudo o que ligares na terra será ligado nos céus, e tudo o que desligares na terra será desligado nos céus", o divino delega ao humano a interpretação quanto a revelação de Deus e interpretação sobre a verdade.

A igreja instituição assume um papel de legítima e exclusiva intérprete dos desígnios de Deus, fato que somado a seu contexto histórico de principal ordenadora e reguladora da sociedade pós império romano, fez imperar uma era de jusnaturalismo regida pelo direito canônico.

Posteriormente, com a separação entre Estado e igreja, a posição da igreja na sociedade se modificou, tomando certa distância formalmente da composição das leis, ou melhor, de sua participação direta dentro da composição política dos Estados, legislativa. Sem, contudo, deixar de exercer sua influência na construção da subjetividade de povos, formando uma ética que implica inevitavelmente numa influência política.

As legislações religiosas então não terão mais efeitos diretos sobre o Estado, mas formarão as populações a partir de ordenamentos internos, condensados nas doutrinas religiosas. Os posicionamentos passaram a exercer normatividade interna, primeiro territorialmente - ao Estado do Vaticano - e em seguida ao âmbito moral dos seus fiéis.

O intento da doutrina social da igreja é de ordem religiosa e moral. Religiosa porque a missão evangelizadora salvífica da igreja abraça o homem na plena verdade de sua existência, do seu ser pessoal e ao mesmo tempo, do seu ser comunitário e social. Moral porque a igreja visa a um humanismo total, vale dizer a libertação de tudo aquilo que 
ISSN 0719-7160

oprime o homem" e ao desenvolvimento integral do homem todo e de todos os homens. (VATICAN, 2011, pg. 56)

Todavia, as interações humanas fazem emergir conflitos sociais seculares que repercutem largamente e ensejam respostas da Igreja. Assim, já relativo ao campo social, desde a Rerum Novarum (1892), a Igreja passa a emitir posicionamentos públicos sobre temas de relevância social, tencionando a relação entre estado e religião, visto que exige de suas fiéis condutas eventualmente incompatíveis com o direito secular, e até mesmo em compreensões diferentes sobre os D.H entre ambas instituições.

Como ponto de partida ao estudo, o Compêndio da Doutrina Social da Igreja reúne os posicionamentos da instituição acerca do mundo e da sociedade, numa lógica interna de direito natural que eventualmente concordará com os direitos humanos e outras vezes não.

O primeiro documento eclesial de cunho social - leia-se, pertinente aos estados modernos, a Rerum Novarum - volta seu olhar para as problemáticas próprias do mundo e da sua relação com o trabalho capital. A Posição interessante quando busca traçar caminho próprio embora com similaridades quanto ao reconhecimento da influência negativa e opressora do capital - ao entender o cenário não enquanto luta de classes, mas aderindo ao princípio da colaboração como forma de transformação da realidade de exploração. (VATICAN, 2011)

Aderindo então a um papel de resistência e oposição as iniquidades do mundo, a igreja reconhece os direitos humanos como fundamentais as sociedades contemporâneas e os entende enquanto esforço para responder as exigências tocantes a dignidade humana, inclusive, sendo a declaração dos direitos humanos de 1948 apreciada pelo Papa João Paulo II como progresso moral da humanidade (VATICAN, 2011).

Contudo, embora as orientações consequentes dos seguintes documentos opinativos da vida social dos fiéis frequentemente coincidam com os direitos humanos declarados, frequentemente também divergem seja por não serem capazes de fugir da visão eurocêntrica dos mesmos, ou por situações em que sua organização teológica interna de suas ideias gera conflitos com os clamores da sociedade civil, fato visto nas questões acerca do aborto ou das uniões homoafetivas.

Põe-se em cheque novamente a separação entre igreja e Estado, visto que este último consiste num espaço democrático, constituído pela população, esta, influenciada por ditames religiosos que clamam inclusive a intervenção do fiel, do leigo não religioso na sociedade, a caráter universal, chama a missão evangelizadora que implica na consequente ação no mundo secular (BOFF, 2016). 
O Conflito se dá, em grande medida, pelo fato da igreja se propor como religio vera, em que a fé é justificada justamente pelo seu fundamento racional. Isso, aliado a uma ideia de universalidade, leva aquele que se destoa dos ditames religiosos a ser considerado como alguém irracional, contra a razão da humanidade, uma impossibilidade de pensamento diferente e sublimação do direito natural enquanto racionalidade de fé e pressuposto moral de humanidade. (D'ARCAIS, 2009).

Partindo deste ponto de vista, a apologética cristã adquiriu um importante significado no decorrer da história do cristianismo. Já em seus primeiros tempos a igreja se preocupava com a justificação racional de suas crenças, como se verifica na seguinte passagem da Primeira Epistola de Pedro:

Mas também, se padecerdes por amor da justiça, sois bem aventurados. E não temais com medo deles, nem vos turbeis; Antes, santificai ao Senhor Deus em vossos corações; e estai sempre preparados para responder com mansidão e temor a qualquer que vos pedir a razão da esperança que há em vós, Tendo uma boa consciência, para que, naquilo em que falam mal de vós, como de malfeitores, fiquem confundidos os que blasfemam do vosso bom porte em Cristo. (c. 3 v. 14-16)

Tal necessidade de defender a verdade da fé se manteve como uma constante por praticamente toda a história cristã e adquiriu feições praticamente inacreditáveis. Desde Paulo de Tarso, que, segundo os relatos do Novo Testamento, frequentemente discutia com mestres nas sinagogas, passando por Agostinho de Hipona e suas polêmicas com as doutrinas filosóficas de seu tempo, culminando, por fim, na escolástica medieval, com a Suma Teológica de Tomás de Aquino, pondo o pensamento aristotélico a serviço da teologia cristã e o Proslógio de Anselmo da Cantuária, propondo uma argumentação para provar a existência de Deus (LARA, 1999), com este último representando, sem sombras de dúvida o auge da justificação racional da fé.

Enquanto a necessidade de fundamentar a razão por trás da fé se manteve ainda como pensamento hegemônico dentro da religião cristã ao longo de toda a história, alguns pensadores considerados "marginais" buscaram demonstrar o absurdo em conciliar fé e razão, ou ainda, procuraram demonstrar que a verdadeira natureza da fé é justamente ser desprovida de qualquer racionalidade. Nesse sentido, o pensamento do pensador dinamarquês Soren Kierkegaard representa uma pedra angular.

Em seu livro Temor e Tremor, Kierkegaard expõe os absurdos da fé através de uma análise do relato bíblico de Abraão sendo ordenado por Deus a matar seu filho Isaac. A obediência a ordem divina representa ao mesmo tempo um terrível crime de acordo com as leis humanas e a mais perfeita conduta de acordo com as leis divinas. O homem é, então, forçado a entender que 
ISSN 0719-7160

a norma geral não Ihe dá suporte, aceitando assim, a exigência divina como algo superior e impossível de ser compreendida. (KIERKEGAARD, 1979)

Justamente nisto reside a beleza e grandiosidade da fé: o cristão aceita a ordem de Deus apesar de suas dúvidas, vivendo em um estado de permanente questionamento interno. Assim sendo, o cavaleiro da fé vive reconhecendo a impossibilidade de se provar racionalmente a fé e ao mesmo tempo crendo nela. (KIERKEGAARD, 1979).

Desse modo, realiza-se uma crítica fundamental a qualquer tentativa de justificação racional da fé, pois se tal fosse possível, a crença não possuiria o significado mais profundo de abnegação de si, que segundo o autor é a verdadeira proposta do cristianismo. Crer no absurdo é, portanto, fundamental para ser um verdadeiro cristão.

Entretanto crer no absurdo também traz consigo os mais variados riscos. Agir de acordo com o dever estabelecido para com Deus significa que, em um potencial conflito entra a ordem divina e as leis terrenas, esta irá ser sobrepujada em relação a aquela. Essa abstenção no respeito as normas gerais (direito, ética, etc) representa em última análise um grave risco para a convivência em sociedade, na medida em que, ao crer na ordem mais absurda, qualquer conduta pode ser tomada como válida, visto que tal conduta pertence a um nível totalmente diferente de compreensão, não devendo o homem questioná-la, ou melhor, sobretudo obedecê-la.

Assim, em pleno século XXI, no qual o medo com relação ao fundamentalismo adquiriu feições latentes, um pensamento que implica em um potencial desrespeito as subjetividades certamente representa um elemento nocivo para a efetivação dos Direitos Humanos.

\section{SEMELHANÇAS E DIFERENÇAS ENTRE OS DIREITOS HUMANOS E A ÉTICA CRISTÃ}

Tendo trabalhado até agora elementos tanto do pensamento cristão quanto dos Direitos Humanos seculares, faz-se necessária agora uma análise comparativa entre estes temas como vistas a verificar em que pontos eles se afastam ou se aproximam.

Em primeiro lugar tem-se o elemento da (a) igualdade. Ora, em todo o período da história antiga os mais diversos povos estabeleceram uma clara distinção entre "nós e os outros", seja na visão helênica sobre os "bárbaros", ou na visão judaica com relação aos "povos gentios". Nesse contexto vê-se que a mensagem cristã quebra com este histórico paradigma, principalmente através da mensagem de Paulo de Tarso, que de acordo com o Novo Testamento, 
batizava tanto judeus quanto pagãos. O mesmo Paulo em sua Epistola aos Romanos, capítulo 3, versículos 9-10 diz algo muito interessante:

Pois quê? Somos nós mais excelentes? De maneira nenhuma! Pois já dantes demonstramos que, tanto judeus como gregos, todos estão debaixo do pecado, como está escrito: Não há um justo, nem um sequer.

Assim, na visão do Apóstolo, a igualdade é estabelecida pelo pecado que é comum a todo ser humano. Muito embora pareça algo negativo, deve-se reconhecer o quão revolucionário tal pensamento é, tendo em vista a época em que foi concebido.

Verifica-se, portanto, que uma visão primitiva de igualdade entre os povos está estabelecida desde os primórdios do Cristianismo, igualdade esta que constitui um valor central dentro da concepção dos Direitos Humanos.

Entretanto cabe ressaltar que Paulo parece manter em seu discurso uma visão muito mais comum para sua época com relação a igualdade entre os gêneros, visto o que afirma na Primeira Epístola a Timóteo, Capítulo 2, versículos 11 a 15:

A mulher aprenda em silêncio, com toda a submissão. E não permito que a mulher ensine, nem exerça autoridade de homem; esteja, porém, em silêncio. Porque, primeiro, foi formado Adão, depois, Eva. E Adão não foi iludido, mas a mulher, sendo enganada, caiu em transgressão. Todavia, será preservada através de sua missão de mãe, se ela permanecer em fé, e amor, e santificação, com bom senso.

Essa mesma visão é teoricamente unânime no Cristianismo durante toda sua história, sendo que exatamente esta passagem é usada até hoje para justificar o fato de mulheres não poderem ocupar cargos relevantes na hierarquia da igreja.

Assim sendo, verifica-se que, embora revolucionária, a visão proto-igualitária estabelecida pelo pensamento Cristão em seus primórdios apresenta problemas quando confrontada a noção de igualdade atualmente estabelecida. Por outro lado, Cristianismo e Direitos Humanos, confluem em sua crítica quanto à desigualdade social e a diferença entre ricos e pobres.

Em seus primórdios a mensagem de Jesus encontra eco essencialmente junto aos marginalizados, oferecendo um alívio através da promessa de redenção na vida após a morte muito bem exemplificada na parábola do rico e de Lázaro. Do mesmo modo o Cristianismo, em especial a Igreja Católica Apostólica Romana, manteve, ao menos discursivamente, uma posição de reprovação quanto ao acúmulo de riquezas mundanas e, ao mesmo tempo, promoveu diferentes iniciativas a fim de amenizar o sofrimento dos desfavorecidos, realizando assim, a efetivação dos Direitos Humanos. 
ISSN 0719-7160

Em segundo lugar tem-se o valor (b) vida, que permanece sendo motivo de um contínuo debate principalmente no que diz respeito ao aborto e eutanásia. Do ponto de vista cristão tradicional a vida é concebida como valor supremo, um sopro concedido pelo próprio criador e que deve retornar a Ele no momento estabelecido de acordo com as leis eternas (VATICAN, 2000).

Entretanto, do ponto de vista dos Direitos Humanos o valor vida pode ser relativizado tendo em vista outros valores como dignidade da pessoa humana e liberdade, por exemplo. Com efeito, no caso da aplicação da eutanásia o que está em discussão é a aceitabilidade de manter uma vida que não poderá ser desfrutada em sua plenitude, mas antes estará fadada ao sofrimento, em outras palavras, uma existência já desprovida de dignidade.

Verifica-se que dependendo do valor empregado pode-se chegar a uma resposta ou outra. Por outro lado, no que diz respeito ao aborto, tem-se o confronto do valor vida com outro valor central: a liberdade. Ora, em tempos em que a luta dos direitos do gênero feminino grita, parece surreal que as mulheres de acordo com as legislações de vários países (com o Brasil incluso) não possam ter autonomia completa sobre o próprio corpo. Verifica-se que tal situação ocorre, em última análise, pela influência da moral cristã sobre a organização social, já que, como foi visto, o Cristianismo mantém a vida como um valor absoluto.

Em terceiro lugar nota-se que no pensamento cristão existe certa (c) visão positiva do trabalho, onde o trabalho aparece como algo indissociável do homem, na figura do responsável pelo cuidado com a criação divina, sendo o trabalho laboral como mais uma face dessa relação como mundo (VATICAN, 2011). Essa posição, hoje majoritária, é opção interpretativa predominante face ao trabalho como consequência por expulsão do Éden (Gênesis 3, 19-23).

Nesse mesmo sentido, a doutrina geral dos Direitos Humanos vincula o trabalho a um promotor da dignidade da pessoa humana e o trata como um elemento importante na sociedade, tanto que todo o artigo XXIII da Declaração Universal dos Direitos Humanos é dedicado a estabelecer os direitos inerentes à figura do trabalhador, como condições justas e favoráveis de trabalho, direito a organização sindical, etc.

Há de ser observado, também, que no século pós disputas entre orientações capitalistas e comunistas, atualmente, nem os direitos humanos ou a igreja se posicionam acerca do capital. Desde o Papa João Paulo II com suas encíclicas criticando tanto o individualismo consumista burguês quanto a organização dos Estados comunistas até a ONU em seus posicionamentos e tratados, abordam sempre o trabalho em sua forma capitalista como um pressuposto, atentandose apenas em amenizar os danos. 
Em quarto lugar, pontua-se um desacordo estabelecido a respeito do conceito de (d) família. É fato notório que uma maior compreensão acerca das relações interpessoais e dos direitos civis fez questionou a visão de família influenciada pela moral cristã, inclusive pelas contribuições cada vez mais crescente de filósofos acerca da questão de gênero e sexualidade, a exemplo de Michel Foucault e Judith Butler, Carole Pateman.

Destaca-se nesse ponto um nó categórico na doutrina da igreja ao abordar a partir da questão da orientação sexual dos indivíduos e sua formação enquanto unidade de família, pois ao passo em que afirma os atos homossexuais "em caso algum podem ser aprovados", logo em seguida afirma acerca dos mesmos:

(Os homossexuais). Devem ser acolhidos com respeito, compaixão e delicadeza. Evitar-se-á para com eles todo sinal de discriminação injusta. Estas pessoas são chamadas a realizar a vontade de Deus em sua vida (...) A pessoas homossexuais são chamadas a castidade. Pelas virtudes do autodomínio, educadoras da liberdade interior. (VATICAN, 2000, pg. 610)

Nó em sua construção pois propõe aos homossexuais a castidade obrigatória, algo totalmente contraditório em termos de liberdade e realização pessoal, além de que ao reconhecer como válida apenas a composição familiar formada por homem, mulher e prole, somada a questão da castidade, torna virtualmente impossível a existência de outras formas de família e, se existentes sendo seus pares ativos sexualmente, não estarão mais na graça do Senhor.

Por fim, no quinto ponto, é a difícil relação entre os próprios pressupostos da religião cristã e os valores de (e) tolerância e liberdade de consciência (principalmente religiosa).

Ora, Jesus afirmou ser o único canal possível entre o humano e o divino, isso implica em uma negação de todas as outras manifestações religiosas, o que por si só é algo problemático. Novamente vem à tona a crise de pretensão de verdade do cristianismo, sendo inevitável a consequência de exclusão do campo verdadeiro outras formas de manifestação religiosa e tensão gerada a partir do imperativo de missão evangélica de converter e difundir a palavra.

Infelizmente, um forte viés fundamentalista tem se articulado a partir de segmentos da igreja, tanto católica quanto protestante, com o intuito de certa "recristianização" da sociedade, aderindo a valores inclusive manifestamente divergentes do próprio evangelho e doutrina cristã.

No meio desse território nebuloso entre os pontos em que a igreja aparece como defensora dos direitos humanos, todavia irredutível em alguns valores internos, grupos sociais aproveitam para articular ideias conservadoras em tese fundamentadas em elementos supostamente Cristãos, o que tem desembocado na crescente onda da Nova Direita (SOUSA SANTOS, 2014). 
ISSN 0719-7160

Não é preciso refletir muito para lembrar o histórico de perseguições promovidas pela maioria das vertentes do Cristianismo frente a outros grupos religiosos devido a discordância em suas crenças.

Assim, tem-se um difícil cenário desenhado: se por um lado há a liberdade de consciência e um apregoamento da tolerância, por outro tem-se a mais influente religião do planeta afirmando ser a única fonte de verdade, criando assim, um ambiente potencialmente conflituoso frente as outras religiões, que somado a essa apropriação de vínculo político/valor intentado pela nova direita, manifesta-se também em luta política.

\section{CONCLUSÃO}

O presente trabalho buscou organizar e comparar materiais que sustentam os direitos humanos a partir de duas perspectivas, uma em tese não religiosa, secular, organizada pelos estados soberanos e articulados principalmente através de organismos internacionais; e outra, a partir do pensamento católico entendendo suas diferenças teológicas e principalmente institucionais, mas trazendo elementos comuns a análise.

Doravante, encontraram-se bifurcações e ramificações dentro das duas vertentes, tornando todo cenário ainda mais complexo. Num ponto, a partir dos direitos humanos de origem secular, a fratura se dá numa crítica ou não dos mesmos, que podem ser entendidos totalizante, universal ou como algo muito segmentado, abarcando direitos apenas dos grupos maioritários, constituindo um grande sistema hegemônico que ainda se mantém como de dominação e exclusão que em sua pretensão de universalidade nada mais faz que elidir os oprimidos.

Esses elementos fundamentais apresentam-se como desafios à igreja: por um lado, a sua pretensão de religio vera, como religião única, inclui um predicado de verdade lógica e culmina numa visão única e absoluta acerca do ser humano, excludente de outras formas de pensamento (D'Arcais,2009). Assim, quando confrontada com questões relativas aos direitos humanos que contrariem sua fé, trava-se o diálogo em pontos dogmáticos.

Contudo, essa união entre Igreja, racionalidade e Estado, edificada pela teologia Cristã, icônica em Tomás de Aquino, encontra divergência mesmo dentro do cristianismo quando Kierkgaard tenciona a pretensão de verdade racional religiosa ao explorar o "absurdo da fé", o limite a sua racionalidade ou sua irracionalidade. 
Só a partir de então pode-se trabalhar as divergências acerca dos direitos humanos numa visão secular ou canônica com intuito de superá-las. Os pontos de confluência e divergência mostrados neste trabalho giram sob o eixo da questão da verdade religiosa e de influência das instituições no mundo, tendo em vista a inexcusável pluralidade de crenças, ideias, religiões e estilos de vida presentes no mundo contemporâneo.

Todavia, os espaços democráticos de representação, principalmente relacionado aos Estados, tem sido ocupado por figuras e movimentos conservadores que se apropriam de elementos em tese religiosos exteriores a própria religião para justificar posições hegemônicas dominantes, totalmente divergentes das demonstradas aproximações - significativas e numerosas - da ideia de direitos humanos secular e religioso. Ou ainda, em outra hipótese, mesmo naqueles que tem sua construção de ideias alinhadas aos posicionamentos religiosos, é injustificável essa obrigação religiosa-secular.

Por fim, compreende-se as dificuldades acerca dos direitos humanos e desse diálogo entre religiosos e não religiosos principalmente em sua relação com espaços democráticos que são, não mais que espaços de disputa de poder em que os interesses e valores se cruzam na tentativa de impor suas perspectivas. Espaços plurais, com crenças diversas, mas que em síntese afastam o indivíduo real das decisões ao manter um mesmo funcionamento no exercício de poder majoritário (FOUCAULT, 2015). 
ISSN 0719-7160

\section{REFERÊNCIAS BIBLIOGRÁFICAS}

BOFF, Bernadete. Cristãos Leigos E Leigas Na Igreja E Na Sociedade. São Paulo: Editora Paulinas, 2016.

D’ARCAIS, Paulo Flores. in: Deus Existe? São Paulo: Editora Planeta do Brasil,2009.

DELEUZE, Gilles. Conversações. São Paulo: Editora 34, 2008.

DOUZINAS, Costas. El Fin de Los Derechos Humanos. Bogota: Legis, 2008.

LANDER, Edgardo. A Colonialidade Do Saber: Eurocentrismo e Ciências Sociais: Perspectivas Latino-Americana. Buenos Aires: Colección Sur Sur, 2005.

FOUCAULT, Michel. A Sociedade Punitiva. São Paulo: Editora Martins Fontes, 2015.

FLORES, Joaquin Herrera. A (Re)invenção dos Direitos Humanos. Florianopolis: Boiteux, 2009.

KIERKGAARD, Soren. Temor E Tremor. São Paulo: Abril Cultural, 1979.

LARA, Tiago Adão. A Filosofia Nos Tempos E Contratempos Da Cristandade Ocidental. Petrópolis: Editora Vozes, 1999.

LUNA, Moisés Saraiva de; OLIVEIRA, Lídia Almeida de. Teoria Dos Direitos Humanos: Debates Jusfilosóficos Críticos Acerca De Sua Fundamentação. RBSD - Revista Brasileira de Sociologia do Direito, v. 4, n. 1, p. 92 - 116, jan. / Abr. 2017.

MARTíNEZ, Alejandro. Fundamentação Dos Direitos Humanos Desde A Filosofia Da Libertação. Ijui: Editora Unijuí, 2015.

SOUSA SANTOS, Boaventura. Se Deus Fosse Um Ativista Dos Direitos Humanos. São Paulo: Cortez editora, 2014.

Direitos Humanos E Interculturalidade. São Paulo: Revista Direitos Humanos, 2009.

VATICANA, Libraria Editrice. Catecismo Da Igreja Catolica. São Paulo: Editora Paulinas, 2000.

Compêndio Da Doutrina Social Da Igreja. São Paulo: Editora Paulinas, 2011. 